\section{Producir Juventud en Chile. Los jóvenes en los saberes, legislaciones e instituciones (1870-1930)}

Producing Youth in Chile. Youngsters in knowledges, legislations and institutions (18701930)

\section{Marcela SaA-EspinozA ${ }^{* *}$}

\section{Resumen}

El artículo analiza la producción de atributos sobre las edades en Chile, desde las últimas décadas del siglo XIX a las primeras del siglo $X X$, con énfasis en la construcción/ producción de ideas de juventud. El análisis se realiza a

\footnotetext{
Este artículo forma parte de los resultados de los proyectos de Investigación VID ENL 013-14, y Fondecyt № 1161126 "La construcción visual de la juventud en Chile. Canon de representación, intermedialidad y sensorium a partir de las imágenes visuales de publicaciones periódicas y archivos fotográficos (1910-1973)".

** Antropóloga, Magíster en Estudios de la Imagen y estudiante de Doctorado en Antropología Social y Cultural por la Universidad Autónoma de Barcelona. Investigadora Universidad de Chile: Proyecto VID ENL013-15 y Co-Investigadora Proyecto Fondecyt №1161126. E-mail: marcelasaae@gmail.com.
}

partir de un enfoque genealógico que indaga en los modos de producir saberes sobre las edades y los efectos de poder resultantes. A partir de fuentes secundarias provenientes del campo de la historiografía, se presentarán discursos y narrativas institucionales y estatales sobre la juventud, rescatando la dimensión de género y etaria, para reconocer cómo desde la escuela hasta las políticas públicas de salud y la legislación se contribuyó a la constitución de ideas sobre las y los jóvenes en el Chile de principios de siglo XX. El corpus analizado lo constituyen textos académicos de historiadores y cientistas sociales, y la centralidad del análisis está puesta en los sujetos invisibilizados por la historia oficial así como en los mecanismos que producían dichas invisibilidades.

Palabras claves: Edades, Juventud, narrativas estatales

\section{Abstract}

The article analyzes the production of age attributes century in Chile, in the last decades of the nineteenth to the early twentieth century. It emphasizes the construction / production of ideas of youth. The analysis is performed from a genealogical approach, exploring the ways of producing knowledge concerning ages and its relations of power. Based on secondary sources from the field of historiography, we will present institutional and state discourses and narratives over youth, rescuing age and gender dimensions, to recognize how from schools to public health policies and legislation the formation of ideas about youngsters in Chile took place in the early twentieth century. The analyzed corpus consists of academic texts written by historians and social 
scientists, and the analysis is mainly focused on those invisibilized by official history as well as the mechanisms that produced these invisibilities.

Keywords: Ages, Youth, state narratives

\section{Introducción}

Desde las ciencias sociales y humanas se ha elaborado una amplia producción de conocimiento sobre las edades, y específicamente sobre la juventud (Reguillo 2012, Pérez y Urteaga 2012, Toro 2012a, 2012 b, González y Feixa 2012, Manzano 2014, Aguilera 2014). En esa línea, el análisis de las edades a partir de un enfoque culturalista ha estado presente a lo largo del siglo XX y se ha consolidado en las últimas décadas, inaugurándose un sub-campo específico al interior de la antropología que se conoce como antropología de las edades (Feixa, 1996).

En este artículo, y a partir de un enfoque genealógico, analizamos la producción de atributos sobre las edades, y que contribuyeron a definir una idea de juventud entre fines del siglo XIX y principios del siglo XX en Chile. Metodológicamente, analizamos críticamente, a partir de una lectura genealógica, los textos académicos elaborados por parte de historiadores y cientistas sociales chilenos en lo referido a la historia y contextos sociales, culturales y políticos que ubican la elaboración de normas, leyes, actividades, espacios y controles sobre los jóvenes. Este tipo de lectura e interpretación indagó en los sujetos invisibilizados, y en los mecanismos que producían dichas invisibilidades. En otras palabras, no sólo se reconocieron los atributos de los jóvenes que aparecen en la historia oficial, y la correspondiente descripción del proceso de su construcción y normalización, sino que se profundizó en aquellas identidades que sólo aparecen a la luz del negativo y que están visibles en cuanto son invisibles a la historia oficial. En esta línea nos referimos principalmente a las mujeres jóvenes. No se trata, en síntesis, de elaborar una historia de la juventud sino de avanzar en una genealogía de lo juvenil.

El análisis de narrativas institucionales, discursos oficiales que provenían desde el aparato estatal y se desplegaron en espacios como la escuela, o el ejercicio cívico y los programas de salud, permite sostener que en el análisis de la edad -y la juventud específicamente-, se debe considerar las dimensiones de clase y género como elementos centrales. De esta forma pudimos dar cuenta que en el ejercicio ciudadano de votar, el establecimiento de la educación estatal y en el control de enfermedades venéreas - que constituyen las políticas y discursos analizadoshubo mecanismos andro- y adultocéntricos que configuraron una específica idea de juventud en Chile.

A continuación presentamos nuestra perspectiva conceptual y metodológica para comprender aquellos discursos y narrativas, así como su importancia en la configuración de identidades sociales. Posteriormente, se presentarán tres apartados: el primero de ellos sobre la edad, la mayoría de edad y la ciudadanía; el segundo sobre las diferenciaciones por género y edad que aseguró la escuela fiscal; y, en tercer lugar, la importancia de los cuerpos sexuados y los discursos sobre las edades para la salud pública. Finalmente, fundamentamos una conclusión que señala los mecanismos estatales que fomentaron y fundamentaron un discurso sobre 
la juventud que impactó las diferentes edades y géneros que componen la sociedad chilena de principios de siglo XX y que han trascendido históricamente como un correlato naturalizado y poco problematizado.

\section{Perspectiva conceptual y metodológica}

\subsection{Antropología de la edad como punto de partida}

Las edades, distintos momentos de la vida que transcurren desde el nacimiento hasta la muerte, tienen significados diferentes según la cultura, tiempo y espacio donde se desarrollen, por lo que cada edad contará con atributos distintos según los códigos socioculturales que hayan sido definidos como adecuados para cada una de estas etapas y en cada sociedad estudiada. Como señala Carles Feixa, reflexionar sobre las edades implica comprender la centralidad de esta categoría en el análisis social. Esto es muchísimo más visible en la actualidad, en la medida en que determinadas edades, como por ejemplo la juventud, tienen mayor protagonismo en la esfera social y mediática, por lo que se constituyen en foco de múltiples análisis por parte de las ciencias sociales, humanas, económicas, políticas, etc.

¿En qué medida la edad contribuye a la conformación de las identidades colectivas?, ¿cómo interactúa con otros factores, como la etnicidad, el género, la clase y el territorio?, ¿es una dimensión central o marginal en la estructura social contemporánea? La ciencia del hombre no sólo ha sido etnocéntrica y androcéntrica, sino que también ha sido adultocéntrica (Feixa. 1996:15).

El estudio de las edades y particularmente de la juventud no implica necesariamente el trabajo desde una perspectiva cultural, ni mucho menos histórico, como el que en este artículo se propone desarrollar. Como señala Oscar Aguilera:

La idea de juventud se ha asumido más como un punto de partida (existe) antes que como un punto de llegada del cual dar cuenta (cómo se ha producido). Al respecto, podemos sostener, además, que no existe una lectura en clave histórica del papel de las producciones culturales, y particularmente la prensa, en la configuración de la idea de juventud en Chile y en América Latina. Esta situación es de vital importancia, si asumimos los presupuestos de Feixa (2008) en cuanto a que la sociedad, vía industrias de la cultura, elabora y oferta un repertorio de imágenes culturales (atributos ideológicos y simbólicos) de lo que es la juventud y con las cuales los sujetos dialogan, negocian, y elaboran sus propias identidades (Aguilera, 2014:143).

La investigación desde las ciencias sociales, desde perspectivas culturales e históricas, sobre cómo se fue configurando una idea de juventud, o una construcción cultural de las edades y la juventud, se ha venido constituyendo en el último tiempo en un campo fértil en América Latina, como lo evidencia la bibliografía consultada (Pérez y Urteaga 2012, Toro 2012a, 2012b, 2014, González y Feixa 2012, Manzano 2014, Aguilera 2014)

El análisis que se propone en este artículo, se realiza a partir del supuesto antropológico de la construcción cultural de las edades y la juventud, el cual sostiene que:

\begin{abstract}
Se trata de estudiar las formas mediante las cuales cada sociedad estructura las fases del ciclo vital, delimitando las condiciones sociales de los miembros de cada grupo de edad (es decir, el sistema de derechos y deberes de cada persona según su grado de edad), así como las imágenes culturales a las que están asociados (es decir, el sistema de representaciones, estereotipos y valores que legitiman y modelan el capital cultural de cada generación). La edad aparece como un constructo modelado por la cultura, cuyas formas y contenidos son cambiantes en el espacio, en el tiempo y en la estructura social (Feixa, 1996: 15-16).
\end{abstract}

De esta forma, una aproximación a las edades y la juventud en específico, permitirá el análisis de la 
división de tareas, responsabilidades y derechos estructurados a partir de la edad, que recorren la organización de la vida social, autorizando acciones y espacios para los sujetos, y que va de la mano con un proyecto moderno de la vida social. En otras palabras, analizar la juventud y las edades es hacer evidente el modelo que cada sociedad contempla en determinado tiempo, para cada categoría de edad;

\begin{abstract}
Más bien de lo que se trata al sostener que la juventud es constructo moderno es de afirmar que se convierte en un asunto sobre el cual la sociedad propone un "modelo juvenil", o sea, un concepto que crecientemente unifica a los sujetos contenidos en su interior y que involucrará decisiones políticas y el surgimiento de un amplio arco de iniciativas destinadas a su caracterización y control (Toro, 2012b:489).
\end{abstract}

Como puerta de acceso al análisis, hemos analizado los marcadores socioculturales que producen la diferencia entre una edad y otra, específicamente entre la juventud y la adultez, o la juventud y la niñez. Los marcadores socioculturales que generan distinciones etarias poseen una compleja configuración espacial y temporal que ha llevado a la edad a constituirse y cargarse de significados diversos según países y tiempos distintos.

En términos generales, se puede señalar que durante la modernidad hubo una compleja red de agentes que ayudaron en la configuración de lo que hoy se entiende por juventud; y entre los dispositivos disciplinarios para la producción de verdad sobre la juventud y sus atributos, encontramos los conocimientos vinculados al cuerpo y la biología-desde distintos lugares como la medicina, psicología, educación, higiene, etc., que ha permitido diferenciar, delimitar y asignar determinados atributos a los sujetos según la edad biológica por la que estén transitando (Saa, 2014). En este sentido, por ejemplo, la llegada de la menarquia y/o menopausia en las jóvenes no sólo es parte de un proceso corporal, sino que ha sido interpretado socialmente, asociando los procesos biológicos a sus posibilidades de acción en la sociedad. De esta forma, y hasta la actualidad, las jóvenes recibirán discursos normativos en cuanto a su cuerpo y sexualidad en el transcurso de dejar la niñez.

Es fundamental reconocer, en esta línea, el peso de las instituciones en la vida de los grupos y la conformación de conocimiento sobre las edades. Las discusiones sobre el cuerpo y las edades no quedan replegados sólo al ámbito científico sino que se utilizan en diversos campos como los educativos, legislativos, judiciales y políticos, por mencionar sólo algunos. Es por ello que en este artículo nos interesa reconstruir los modos en cómo los atributos socioculturales de las edades se introducen a través de diversos discursos sociales, produciendo a su vez conocimientos sobre las edades y particularmente la juventud, y permitiendo el libre o delimitado ejercicio de acciones en sociedad. De allí que sea estratégico en el análisis sobre la construcción de edades y específicamente sus marcadores, preguntarnos por los cambios históricos y la incidencia que estos han tenido en la generación de diferenciaciones entre las edades. Dichos atributos tienen una lenta y compleja manera de afianzarse en el ámbito socio-cultural. Es por ello que hemos optado por rescatar la dimensión histórica de su configuración, reconociendo los cambios y estabilidades del discurso social que permiten su definición. No se propone una historia de los atributos juveniles ni de las edades en general, sino conocer y reconstruir a partir de ciertos archivos, las formas de nombrar y delimitar aspectos sobre juventud, es decir conocer cuáles eran sus espacios y prácticas. 
A partir de la revisión de historiografía sobre las edades y la juventud chilena, se reconocen avances en la producción de conocimiento sobre dichas identidades, por lo que queda profundizar en otras dimensiones que no son siempre visibles debido a los focos y espacios analizados. En ese sentido, quedan fuera otras dimensiones de lo juvenil que no se inscriben en el análisis de la juventud masculina, urbana, blanca y moderna. Como señala Pablo Toro: "De tal manera es que ámbitos tales como lo popular, lo étnico, o el eje de análisis en torno al género resultan perceptibles solamente a través de indicios, casi por oposición, en este ejercicio de comprensión" (2014:266-267). De esta forma, los atributos de la juventud serán observados de manera relacional, evidenciando los discursos en negativo, el exterior constitutivo, y utilizados muchas veces para definir, normalizar y delimitar a ciertas edades o dimensiones de género. En este artículo mostraremos que las jóvenes y los jóvenes, en el discurso institucional estatal serán tempranamente tratados de maneras distintas, permitiendo con ello que se articulen el discurso sobre las edades y el género en ámbitos como la salud, la legislación y la escuela.

\subsection{La genealogía como perspectiva analítica}

La genealogía como perspectiva, para efectos teóricos y metodológicos, proviene de las nociones desarrolladas por Michel Foucault (2008). Desde el modelo genealógico se busca reconocer las matrices de producción de verdad $^{1}$ en torno a distintos elementos culturales. Es un ejercicio de reconocimiento de las continuidades y discontinuidades, donde los recortes genealógicos están dados por

La verdad para Foucault no es esencial, objetiva ni inmutable, sino construida, histórica y posee la característica de ser una voluntad de verdad que encierra un sistema de exclusión. relaciones de poder y saber entre elementos y discursos. M. Foucault, más que preguntarse por un origen se pregunta por las emergencias de ciertos saberes, rastreando las múltiples condiciones de posibilidad que permiten esta emergencia.

Es por eso que el ejercicio analítico desde esta perspectiva consiste en pasar del conjunto de análisis propiamente crítico al genealógico, lo que quiere decir que no sólo basta con constatar la emergencia de categorías identitarias -los jóvenes en nuestro caso- sino en comprender sus posibilidades de existencia. Así, el estudio de la juventud que contemple o se adscriba a una perspectiva genealógica debe conocer y hacerse cargo de radicalizar la posición culturalista, por lo que no bastaría con describir un fenómeno, sino lograr conectar el proceso y los sucesos que posibilitaron la existencia de la categoría en estudio.

Desde la perspectiva genealógica, nuestro interés está puesto en visibilizar los mecanismos de producción de verdad que permitieron la construcción de una idea de juventud y específicamente relevar aquellos discursos y estrategias materiales que acompañaron la construcción de dicha idea y otras edades desde fines del siglo XIX y principios del XX en Chile. De igual manera, debemos señalar que el trabajo propuesto no tiene como fin la elaboración de una historia de la juventud, sino de ubicar/reconstruir las condiciones de posibilidad de los discursos sobre la juventud. Es decir, rastrear las articulaciones que permitieron la producción de un cuerpo juvenil, reconstruir las significaciones resultantes que visibilizaban a esta juventud, y establecer las conexiones entre el ámbito de las ideas y de lo material en relación a este sujeto. 
A partir de un análisis previo (Saa, 2014), pudimos reconocer el poder que la industria cultural específicamente a través de la publicidad- tuvo en la conformación de ideas y atributos sobre el cuerpo de las jóvenes, a partir de la producción y difusión de imágenes sobre éste grupo. Creemos que profundizar en una genealogía de lo juvenil, supone el reconocimiento de otros discursos y espacios de producción de conocimiento sobre las jóvenes.

Es así como, para efectos de éste artículo, analizamos los discursos institucionales como fuentes desde donde emergen ideas para la normalización de las edades y la juventud. En particular, nosharemoscargo demostraraquellos momentos anticipatorios de la constitución discursiva en torno a una idea de juventud femenina, por lo que buscamos evidenciar los procesos y mecanismos desplegados desde el mundo institucional para la conformación de ciertos discursos hegemónicos sobre los grupos de edades y los jóvenes varones, para dar cuenta de las potenciales estabilidades semióticas y culturales que fueron produciéndose en torno a la idea de jóvenes mujeres.

Cabe señalar que cuando nos referimos al análisis de los discursos institucionales estaremos trabajando específicamente las normas, que funcionan como dispositivos para la regulación de aquella configuración semántica y cultural sobre los atributos de las edades. Rescatar la noción de dispositivo (Foucault, 2005, 2009), y comprender su uso analítico como bisagra entre cuerpo y población, poder y saber, busca visibilizar la heterogeneidad de estrategias que se vinculan en el plano semántico y cultural para la construcción de dichas categorías, y que en términos analíticos permiten comprender la manera en cómo se elabora y fijan aquellas configuraciones discursivas en torno a las edades y a la juventud principalmente.

El dispositivo entendido como bisagra permite tender las relaciones necesarias y funciones particulares para que el saber y el poder se desplieguen en el cuerpo y la población. Esta bisagra que articula saber/poder y el cuerpo/ poblaciones, nos permite reconocer distintos mecanismos de conexión y red que permiten una función estratégica de las relaciones de poder y saber sobre el cuerpo y la población. En esa línea hemos reconocido la implementación de determinadas normas sobre la población y su accionar como dispositivo en la configuración identitaria. La gubernamentalidad se presenta como el proceso, siempre localizado, de generación y gestión de políticas de acción sobre el individuo y la población, y de allí se derivan las normas que pueden ser pensadas como un dispositivo de control. Para el caso que abordaremos, debemos preguntarnos en qué medida la norma como un dispositivo puede ser reconocida en los discursos institucionales estatales de la época que nos interesa conocer.

En base a lo anterior es que reconoceremos en las normas chilenas de fines del XIX y principios del siglo $X X$, relacionadas a la educación, salud y derechos cívicos, como formaciones discursivas que se constituyen en dispositivos que articulan discurso y despliegan tecnologías prácticas respecto a como se segrega a la población y definen ideas sobre los grupos de edades. 


\section{Hallazgos: Saberes, Legislaciones e Instituciones}

\subsection{La conformación adultocéntrica de la ciudadanía chilena}

Durante el siglo XIX, el proceso de conformación de la ciudadanía chilena se vio convulsionado por una serie de reformas que permitieron la paulatina construcción de un estado democrático. El derecho a sufragio de una población cada vez mayor fue una de las expresiones de esta nueva política, la cual funcionó también como legitimación del estatuto de ciudadano, estableciendo deberes y derechos a la población. Esta comprensión de la ciudadanía estuvo marcada por distinciones donde la edad y el género definieron las características de la inclusión en esta categoría.

En términos generales, se puede señalar que las graves faltas ocurridas en los procesos de elección de representantes políticos llevaron al país a una serie de transformaciones que buscaban transparentar y aumentar la cantidad de electores en el Chile de mediados de 1800. Este tipo de cambios se materializaron a partir de la Ley electoral del 12 de noviembre de 1874, la cual, como señala Alfredo Joignant (2001), debió articular no sólo una serie de discusiones y puntos de vista para llevar a cabo la correcta implementación de esta ley, sino también la aplicación de diversas tecnologías que permitieran establecer una nueva simbolización del acto de votar. Esta ley no sólo amplió el caudal electoral, ya que eliminó la renta como condición para poder votar, sino que además y por primera vez desde las elecciones de 1810, incorporó la preocupación por garantizar la transparencia y el carácter público del voto, lo que ayudaba a reglamentar la idea de lo que constituía la democracia.
En cuanto a las edades, esta nueva ley mantenía la mayoría de edad establecida por la Constitución de 1833, que oscilaba entre 21 a los 25 años para ejercer el voto por parte de los hombres de acuerdo a su estado civil: "La ley de 1874 extendió el derecho a sufragio a todos los hombres mayores de 21 años, si eran casados, o 25 años, si eran solteros, eliminando el requisito de renta que había establecido la Constitución de 1833, aunque mantuvo el requisito de saber leer y escribir" (Joignant, 2001: 248). De esta forma, la ampliación se enmarcó dentro de las nuevas reformas constitucionales que incorporaba una cantidad mayor de población para el ejercicio democrático, aunque continuaban teniendo características fuertemente androadultocéntricas.

La relativización, que se expresaba con respecto a la mayoría de edad según el estado civil desde la Constitución de 1833, y que se mantenía con las reformas a la Ley Electoral de 1874, indicaban que era el estado civil la garantía de que el sujeto que ejercía el voto tenía el discernimiento y algún grado de madurez y/o adultez alcanzado. De esta forma, la soltería se presenta en el discurso legislativo como el negativo, lo otro, aquello que es garantía de cierta inmadurez o estado infantil del sujeto, e imposibilitaba el sufragio dentro de un régimen y concepción de ciudadanía que se construyó y entendió desde una matriz adulta. En otras palabras, se puede observar que la mayoría de edad se considerará como marcador de adultez, no basado en el criterio de la edad sino del estado civil, que procuraba ser más exacto y sensato para reconocer la adultez y las responsabilidades cívicas.

Muchas de las dificultades que durante el siglo XIX y primeras décadas del siglo $X X$ se presentaron en las inscripciones $y$ 
posteriormente en las mesas del sufragio, tenían su origen en los juicios y valoraciones acerca de quién tenía el derecho de voto. Señala Joignant (2001) que incluso después de la ley de 1874 siguieron existiendo dificultades en relación a la legitimidad de aquellos que se inscribían y querían votar, haciendo alusión a los juicios de la junta electoral, que muchas veces llevaron a que algunos no pudieran inscribirse como parte del nuevo electorado simplemente porque no tenían aquellas características "esperables" de la población electora. Utilizando un criterio discrecional y subjetivo, quienes estaban a cargo de las mesas electorales podían impedir el sufragio a determinados sujetos si el aspecto que presentaban no concordaba con la edad que debía tener, incluso frente a la documentación que acreditase lo contrario:

En este caso, la propia ley no era muy precisa puesto que señalaba, en su artículo 17, que en caso de duda sobre la edad de la persona, "la junta decidiría de su admisión a partir del aspecto del individuo". Este último problema nos remite a la muy débil credibilidad de los documentos que corroboraran la identidad de los individuos, respecto de lo cual la propia ley se hacía eco elevando como medio de prueba aspectos tales como el "título de una profesión o de un empleo", cuyo ejercicio le correspondería a una persona mayor (Art. 17) (Joignant, 2001: 254).

Es relevante reconocer esta distinción, ya que la mayoría de edad funciona en el plano jurídico para establecer la capacidad del individuo de hacerse responsable en el plano penal pero también en lo civil, y este tipo de situaciones se mantendrán durante el siglo XIX, y hasta 1929, momento en que se define con la Ley 4.554 una mayoría de edad de 21 años para ejercer el sufragio y se amplia como mayoría de edad civil universal para los hombres. Observamos entonces que en la propia legislación hay una propuesta acerca de la concepción y atributo de madurez de las edades. Finalmente, y como explica este autor, sólo con la implementación del sistema de huellas digitales en 1925 y la fijación del lugar de votación en la década de 1960, se pudo gestionar de mejor manera, y más certera, la inclusión de aquellas identidades que constituyen la ciudadanía, y tanto la discrecionalidad aplicada a los sujetos como la discriminatoria actitud en torno a una imagen apropiada de la edad llegarán a término.

A partir de lo anterior, puede reconocerse que el establecimiento de la mayoría de edad, en tanto jerarquización dentro de la estructura social, puede ser comprendido históricamente como una distinción cambiante. Estructurado bajo los supuestos atributos de las edades, y mediado por complejas simbolizaciones culturales según épocas, en general vemos que es una distinción que se constituye desde una matriz adultocéntrica. En otras palabras, la definición del joven se constituye en lo negativo de la adultez. La ciudadanía que se asienta desde el nacimiento de la República en Chile, lo hace principalmente a partir de varones mayores de edad muy distintos a los actuales, en la medida en que esta jerarquización difería según una serie de acciones societales. La bibliografía referente a la ampliación del sufragio en Chile durante el siglo XX es abundante y mucho más sistemática en temas referidos a la segregación y luego inclusión de las mujeres. Sin embargo, hemos podido reconocer que no hay una lectura con perspectiva de las edades acerca de esta apertura electoral, por lo que se invisibiliza cuál fue la idea de generación y edad desde la que se construyó la ciudadanía (masculina) en Chile.

Si bien los hombres y ciudadanos jóvenes tuvieron dificultades para lograr ejercer muchas veces sus derechos ciudadanos, el caso de la 
mujer es un proceso más lento y discriminatorio, donde el criterio de la edad pasa mucho más inadvertido que en el caso de los varones.

Sobre este tema, es posible señalar que en Chile el movimiento feminista tuvo entre sus intereses principales reivindicar el lugar social de la mujer, por lo que el derecho al sufragio representaba una de las tantas expresiones de igualdad en materias de género que se buscó alcanzar durante el siglo XX. Sin embargo, buena parte del movimiento feminista que se articuló por el derecho al sufragio eran mujeres de clase alta con una restrictiva visión acerca de la juventud.

El derecho al sufragio femenino tuvo momentos de auge durante la primera mitad del siglo $X X$, tanto en su discusión como en su implementación legislativa. Con el Decreto de Ley N. 320, del año 1931, se estableció bajo el gobierno de Carlos Ibáñez del Campo el derecho a que las mujeres votaran en las elecciones municipales. Esto sólo se transformaría en Ley el año 1934 (Ley n. 5357), y recién en abril de 1935 las mujeres pudieron ejercer el voto en este tipo de elección. En este sentido, si bien la Ley 5.357 se presentaba como un avance en materia de derechos para las mujeres, incorporaba en su interior una serie de condicionantes económicas y societales que tenían semejanzas con las otorgadas para el varón cien años antes, en la primera mitad del siglo XIX.

Entre las condicionantes del decreto de Ley 320 de 1931, transformado en ley de elecciones municipales del año 1934, se estableció que sólo podrían votar mujeres mayores de 25 años, propietarias de un bien raíz y con el pago de impuestos correspondiente al rol de patentes municipales. A diferencia del estado civil, que era aplicado a los hombres en el siglo XIX, fue la capacidad económica aquello que condicionó tempranamente el sufragio femenino, lo que a su vez indica en qué medidas se fue mujer y adulta en aquella época. Esto puede ser explicado, entre otras cosas, por los intereses de las clases dominantes acerca del control político que significaba un aumento significativo de la población femenina si votase, pero también porque fueron las clases media-altas las que se articularon por este derecho.

La edad de sufragio, en 1929, se estableció en los 21 años para los hombres. Sin embargo, la condición de género es la única que explica que para las mujeres fuese a los 25. De esta forma, el marcador de adultez que significaba durante el siglo XIX y principios del siglo XX la mayoría de edad, permitieron definir de manera más exacta los atributos e ideas asociadas que existían en torno a los grupos de edades. Es decir, la comprensión de esta identidad social (adultos) nos entrega ciertas pistas (en negativo) acerca del lugar social que ocupaban los otros grupos etáreos (jóvenes).

\subsection{Educación diferenciada por género y legitimada por el Estado}

Como señala Pablo Toro, "un factor que ha desempeñado un papel importante en la formación de las condiciones de posibilidad de la juventud como un grupo social reconocible ha sido la escolaridad" (2012b: 289). De allí que para un análisis histórico y/o genealógico, la escuela constituya un espacio indispensable en la comprensión de la configuración de la juventud, en la medida en que permite comprender "la normalización de ellos, para su formación como futuros conductores de la nación" (Toro, 2012a: 74). 
La educación, como derecho garantizado por el Estado chileno, se establece a partir de diferentes procesos legislativos entre los años 1873 y 1879 . Fue durante la gestión de Miguel Luis Amunátegui, como Ministro de Educación, que se estableció en 1879 la Ley de Educación Secundaria y Superior, que garantizaba la educación secundaria obligatoria y estatal para los niños y jóvenes en Chile.

En el caso de los liceos femeninos fiscales, como relatan Ramos y Sepúlveda (2010), estos aparecerían en la década de 1890. A diferencia de los liceos fiscales para los varones, que dependían del Ministerio de Educación, los liceos fiscales femeninos dependieron del Ministerio de Justicia e Instrucción Pública, por lo que se imposibilitaba un ingreso directo a la educación superior. Las diferencias más relevantes de la educación fiscal que se impartía a niños, niñas y jóvenes en la segunda mitad del siglo XIX, se encontraban delimitadas por las expectativas $y$ posibilidades definidas para cada grupo:

\footnotetext{
El disciplinamiento a través de la educación habría sido percibido desde temprano, en clave ilustrada, por los fundadores del nuevo orden republicano en Chile como un factor crucial para el logro del progreso. La imbricación mutua de los aspectos físicos y conductuales era reputada como indispensable (Toro, 2014: 264).

En el otro extremo, se entendía entonces que el que los liceos femeninos fiscales no tuvieran vínculo con la Universidad era una expresión que la expectativa de este tipo de educación no era prepararlas para cursar estudios superiores. Así, se reforzaba aún más la idea de que el espacio de la mujer era el ámbito privado del hogar y la familia (Ramos y Sepúlveda, 2010: 60).
}

Esta realidad expresa las paradojas políticas y formales que enfrentó el derecho a educación a fines del siglo XIX en Chile. El decreto de Amunátegui en 1877, Ministro de Justicia e Instrucción Pública en ese momento, permitía el ingreso de las mujeres a las universidades para cursar estudios superiores. Sin embargo, pese al esfuerzo político y cultural que esto significaba, el Estado aún no asumía la responsabilidad de estudios secundarios a mujeres. Los liceos femeninos existían en Chile desde el siglo XIX, pero eran una iniciativa privada de alto costo $y$ estaban diseñados para las señoritas y/o niñas de la alta sociedad. De esta forma, las mujeres que ingresaban y habían dado la lucha para el ingreso a la educación superior respondían sólo a la clase alta chilena.

El debate que generó la polémica del ingreso de la mujer a la educación superior amplió el espectro discursivo de la sociedad en relación a qué se esperaba de las mujeres jóvenes en cuanto a sus derechos y deberes. De esta forma, ya no se proyectaban sólo como cuerpos activos en el espacio privado, sino también como competencia en el espacio público. De esta manera, el decreto de Amunátegui de 1877 reafirmaba que se avecinaba una nueva etapa donde las mujeres tendrían mayor visibilidad en el espacio público y el Estado debería tomar iniciativa y participación directa en gestionar equidad educativa a su población:

\footnotetext{
He ahí la importancia del Decreto Amunátegui: borrar las amarras de la costumbre por medio de la ley. ¿Lo intuyó así Amunátegui? Debemos recordar que Miguel Luis Amunátegui fue un típico hombre público del siglo XIX: educador, político, historiador, periodista. (...) Si Amunátegui actuó conscientemente o no, es algo que no se puede afirmar sin una documentación que así lo afirme; pero lo seguro es que su figura es una fiel representación del siglo XIX (Sánchez, 2006: 513).
}

Lo que indica Sánchez es que más allá del acto en sí-que permitía a un selecto grupo de mujeres de clase alta ingresar a determinadas carreras en las universidades chilenas-, el decreto de Amunátegui fue parte de las estrategias políticas 
necesarias para abrir la discusión sobre la educación secundaria femenina garantizada por el Estado.

Una vez que el Estado garantizó la educación en liceos fiscales femeninos, aparecieron una serie de restricciones y diferenciaciones con la educación masculina. Los programas de educación masculina regían de forma universal, es decir eran aplicados a colegios particulares e incluso a los liceos femeninos. A partir de la garantía estatal de los liceos femeninos, se modificaron programas y se configuraron programas distintos por género, lo que reforzó que la escuela tempranamente comenzara a transmitirvaloressegregados. El reconocimiento de estas reglamentaciones, y la implementación de la educación para varones y mujeres en Chile, nos permite inferir algunos discursos sociales que referían a esta identidad juvenil, y a su vez reconocer el curriculum como un dispositivo de normalización de saberes diferenciados en la configuración de lugares y expectativas sociales para las y los jóvenes.

El espacio escolar y su garantía estatal, como señala Pablo Toro (2010), produjo procesos de normalización a partir de mecanismos de homogeneidad, donde el uniforme escolar por ejemplo, y la distinción discursiva del escolar versus los muchachos, marcaron durante el último cuarto del siglo XIX la confección identitaria de la juventud. P. Toro (2012a), también señalará que en el año 1868 existía ya el discurso acerca de la juventud como conductora de la nación, formada en la educación pública, idealizando y vinculando los discursos de la escuela y de la educación superior con los ideales de la nación. Si observamos en este mismo periodo cuál es la vinculación entre educación para jóvenes mujeres y expectativas de nación, observaremos a la luz de lo que relata K. Sánchez (2006), que era la reproducción del espacio privado lo que se vinculó en excluisva a este grupo:

\begin{abstract}
Ante toda esta polémica de la necesidad de instruir a la mujer y la cantidad de ésta que debiera recibir, es interesante destacar que la opinión generalizada de que la mujer es quien forma los futuros ciudadanos significa que ella ocupa un rol extremadamente relevante en la sociedad, pese a no estar en el espacio público. Se trata de un deber, una misión que se cumple en el hogar, espacio privado por excelencia (Sánchez, 2006: 519).
\end{abstract}

En términos generales, las prácticas y discursos que se llevaron a cabo en la escuela, como en la opinión pública y en el plano jurídico, provocaron una segregación de género garantizada institucionalmente, lo que ayudó a una naturalización de estos atributos en la esfera cultural. Podemos decir que durante las últimas décadas del siglo XIX hay reportes de una configuración de lo juvenil en Chile, donde la escuela es un configurador central en los mecanismos disciplinarios sobre este grupo. Los jóvenes, como estudiantes, tienen un momento de visibilidad importante a comienzos del siglo XX con la creación de la FECH y donde surgirá una "identidad estudiantil" como lo han retratado Salazar y Pinto (2002), y que se ha transformado en uno de los hitos o acontecimientos que visibiliza y hace emerger en la temprana modernidad chilena al actor juvenil. Sin embargo, a la luz de la revisión historiográfica poco sabemos de la configuración de la identidad juvenil femenina que se venía conformando durante este tiempo, y que a luz de una lectura genealógica puede ser rastreada a partir de las formas de nombrar (las señoritas) y de las identidades en negativo que están presentes, pero que no contienen una estabilidad semiótica tal como la de los jóvenes varones (niñas, señoritas, muchachas). 


\subsection{La salud y la preocupación por el control de los cuerpos}

En Chile, a principios del siglo XX y hasta fines de la década de 1930, la tuberculosis fue la principal causa de muerte. La población arrastraba una serie de prácticas nocivas de salud, entre las cuales se cuentan el alcohol y los problemas vinculados al crecimiento de las ciudades y el hacinamiento. Por otro lado, diversas enfermedades referidas a la salud sexual y reproductiva golpeaban fuertemente a sus habitantes en general. Ya en 1872, un Decreto de Ley buscó promover y enseñar higiene en las escuelas, pero fue un fracaso total porque no llegó a la amplia población que necesitaba aprender normas y prácticas para mejorar sus condiciones sanitarias, y el conocimiento estuvo confinado en las escuelas de los sectores acomodados del país.

Durante la década de 1920, como señala Catalina Labarca (2008), el Estado chileno asumió una mayor responsabilidad en lo vinculado a la salud de su población. Esta tarea, que venía lentamente desarrollándose desde el siglo XIX a partir de la implementación de políticas de salud, sólo benefició a las clases altas. En 1925, y a partir de los cambios en el Código Sanitario y del reconocimiento que la salud era un derecho que el Estado debía garantizar a sus ciudadanos, y por lo tanto disponer fondos para ello, se presentan nuevos tipos de campañas que vendrían principalmente a prevenir aquellas prácticas vinculadas a la salud sexual y reproductiva. La discusión legislativa de aquel momento reivindicaba que la prohibición y el castigo al contagio de estas enfermedades (tal como lo proponía el Código de 1925) no eran la solución e invadían la vida privada de la ciudadanía. De esta forma, serían la educación y la prevención la fórmula para mejorar la salud de los chilenos.

El interés por la prevención de este tipo de enfermedades se justificaba porque, a mediados de la década de 1930, la tasa de mortalidad infantil en Chile era una de las más altas del mundo y "de 1900 a 1935, trescientos de cada mil niños no lograron sobrevivir más de un mes" (Rinke, 2002: 97), siendo la transmisión congénita de la sífilis lo que producía la mayor cantidad de muertes, afectando al 10\% total de la población. Es por estas cifras que se reconoce que las enfermedades venéreas impactaban directamente la vida cotidiana de los chilenos y en 1935 constituían la sexta causa de muerte en el país. Estas enfermedades -junto al alcoholismo y la prostitución- sirvieron de base para los discursos raciales con base en la eugenesia, que se desplegaron en Chile a fines del siglo XIX, y que se tradujeron en prácticas y discursos asociados al cuidado de la raza y el cuerpo.

Labarca (2008), señala que este tipo de enfermedades, y las campañas de información y educación a partir de manuales, fueron de vital importancia para que el Estado chileno, apoyado científicamente en la disciplina de la Eugenesia, pudiese mantener una población más saludable y acorde al proceso de modernización que estaba implementándose. Existía, como evidencia la autora, un interés en llegar a la población juvenil (sin distinción de género, aunque sí de clase) porque eran considerados como los principales agentes de contagio y de prácticas nocivas, y para 1929 eran el grupo con mayor prevalencia de estas enfermedades, lo cual fue explicándose como algo natural o escencial, simplemente por su condición de edad: 
Para los manuales, el "único propósito de la vida" era "su conservación", de modo que todos los seres vivos buscaban siempre "reproducir a un ser semejante". Siguiendo la línea freudiana, los manuales afirmaban que la sexualidad era propia del ser humano desde su nacimiento y que los cambios más profundos los experimentaba durante la pubertad. El "despertar sexual de los jóvenes" era entendido como parte del crecimiento adolescente, y la castidad era considerada como un "absurdo inconcebible" en cuanto impedía la reproducción (Labarca, 2008: 112).

El discurso que provenía del Estado buscaba entregar toda la información a una población que reconocía como sexualmente activa. Sin embargo, también promulgó imágenes acerca de los deberes y responsabilidades de cada género en cuanto a su salud, ya que eso formaba parte fundamental de tener una mejor patria. Se difundía un ideario de sexualidad que dictaba como obligatoria para los heterosexuales, en pareja y preferiblemente casados. De esta forma, a partir del discurso de la eugenesia se reforzaban los modelos cristianos de identidades de género en Chile.

A su vez, el "despertar sexual de los jóvenes", que se consideraba por esa época la explicación primera al comportamiento de la juventud, se entiende dentro del contexto latinoamericano y chileno por el ingreso de discursos referentes a la psicología. Como señala Alarcón (2002), la psicología en América Latina impuso tempranamente la idea de tener una orientación científica y aplicada; de esta forma explicitaba un acercamiento a los métodos científicos más que a la filosofía. El Estado propuso en 1889 el ingreso de destacados psicólogos alemanes al Instituto Pedagógico Nacional, como lo fueron Jorge Enrique Schneider y Guillermo Mann, que se preocuparían de enseñar la psicología científica de aquel momento. Posteriormente, estos psicólogos abrirán en 1908 el primer laboratorio de psicología experimental. En la década de 1920, aún existía este laboratorio de psicología y otro se abrió en la Universidad Católica.

Uno de los discursos más difundidos -a nivel mundial- fue impulsado por Stanley Hall en 1904, a partir del tratado sobre adolescencia que escribiría. Estas ideas Ilegaron a Chile a partir principalmente de estos espacios de laboratorio y la importación de libros. La psicología introduciría aquellos elementos que permitían comprender -y fijar- estos sentidos biológicos y naturales sobre los temperamentos y sexualidades de la población juvenil particularmente:

\begin{abstract}
Para [Stanley] Hall, la adolescencia es: Una edad especialmente dramática y tormentosa en la que se producen innumerables tensiones, con inestabilidad, entusiasmo y pasión, en la que el joven se encuentra dividido entre tendias opuestas. Además, la adolescencia supone un corte profundo con la infancia, es como un nuevo nacimiento (tomando esta idea de Rousseau) en la que el joven adquiere los caracteres humanos más elevados (Deval, 1998:545) (Dávila 2004: 87).
\end{abstract}

Estas nuevos discursos disciplinares sobre la población en condición juvenil, pero identificada como adolescencia, se enmarca en una concepción de la psicología evolutiva, como señala Oscar Dávila (2004), y que se relacionó de manera coherente con la Eugenesia en Chile. De esta forma, observamos que en la discusión sobre salud en Chile hay tempranamente una incorporación de disciplinas con fuertes tendencias evolutivas que nombraron y clasificaron tempranamente los comportamientos de cierta población.

Un último elemento son las concepciones raciales que se propusieron desde la Eugenesia en Chile a través de modelos corporales $-y$ morales- correctos $\mathrm{y} / \mathrm{o}$ deseables. Estos 
discursos acerca de la raza muchas veces explicaban las conductas sociales de la población. Por ejemplo, las enfermedades de transmisión sexual y las prácticas de prostitución y alcoholismo se explicaban desde aquella matriz discursiva, que en general reivindicaban una mejoría social a partir de la eliminación de ciertos sujetos y prácticas. Durante las primeras dos décadas del siglo XX, hay una proliferación de estos discursos con una gran resonancia en el espacio socio comunicacional, siendo Nicolás Palacios y su texto "La raza chilena" un claro ejemplo de ello. En 1925, las dificultades sociales que produjeron las enfermedades venéreas en el país se discutieron a su vez en el "Decreto Ley sobre defensa de la raza", lo que nos indica que la categoría racial funcionó para abarcar una serie de dificultades en el ámbito de la salud, comprendidas a partir de la idea de déficit racial.

\section{Conclusiones}

Las tres narrativas institucionales analizadas: escuela, legislación y ciudadanía, y reformas de salud, permiten observar un panorama social e histórico amplio de producción de normas sobre las edades y la juventud. A su vez, y como pudimos observar, los clivajes de clase y género no pueden aparecer por fuera del análisis de la edad. Los discursos provenientes desde el Estado se articularon en red, a partir de diferentes estrategias y en base a saberes que se desplegaron en dispositivos específicos de regulación para la población, como normas y leyes, hasta espacios y derechos.

A partir de lo encontrado se puede sostener que durante la segunda mitad del siglo XIX y la primera mitad del siglo $X X$, se produjo un discurso social sobre la edad que fue definiendo con mayor claridad los atributos que constituyen determinados momentos de la vida, así como las responsabilidades asociadas a ellos -al menos en el plano cívico. De esta forma, el artículo 17 de la ley de 1874 expresa de modo indicial esta puesta en marcha, que ya está en la esfera cultural chilena, sobre los deberes que un adulto debiese tener, explicando por negativo los deberes y espacios que otras edades cumplen. La producción de sentidos que se expresaron en la idea de ciudadanía, se construyó sobre una matriz adultocéntrica, por lo que los marcadores de edad que en la actualidad remiten a la juventud (la mayoría de edad, por ejemplo), a principios de siglo XX aún no estaban representando dicha idea. La "responsabilidad cívica", como vimos, fue interpretada como una tarea que involucra madurez y se alcanza a partir de ciertas condiciones sociales más que biológicas (matrimonio, bienes o servicio militar), y desde allí se configuran en marcadores de adultez, y marcadores en negativo sobre la juventud.

En segundo lugar, podemos concluir que el espacio de la escuela o de la educación institucionalizada-así como los debates sociales y políticos que éste tópico produjo- fue un importante agente de producción de identidad juvenil y contribuyó a configurar una identidad principalmente masculina, aquella que más se ha estudiado pero no necesariamente la única expresión de juventud. La juventud femenina, a principios del siglo XX, estará en las escuelas (religiosas, privadas y fiscales) reproduciendo los discursos y saberes sobre el espacio doméstico y privado. Se las nombrará como muchachas, niñas y señoritas, por lo que están constituyéndose en una identidad social con atributos fijos, aunque su estudio es bastante periférico e invisibilizado. 
La transmisión de la cultura encuentra en la escuela el espacio autorizado para el mantenimiento del sistema cultural, al menos en la sociedad occidental. Es por ello que los mecanismos utilizados en las escuelas para enseñar determinadas materias a las mujeres y otras a los hombres, así como las posibilidades y expectativas que para cada género se configuraron como naturales en su vida adulta, nos permiten comprender la configuración de un discurso hegemónico acerca de lo que se espera de cada género y la educación que debe impartírseles, identificando configuraciones diferentes en el caso de los jóvenes varones y de las mujeres.

En tercer lugar, y en cuanto a la salud, observamos narrativas más explicitas sobre el cuidado del cuerpo. Así, tanto de la mano de la Eugenesia como de la Psicología Evolutiva, los comportamientos y problemas de salud de la población juvenil fueron configurándose y explicándose desde una matriz científica que transformaba los discursos morales y religiosos en discursos naturales y objetivos, manteniendo así una regulación sanitaria de la población según intereses de corte colonial y evolutivos. De esta forma, el nuevo paradigma científico y moderno permitía asegurar la hegemonía de los discursos asociados al cuerpo juvenil.

En términos globales, podemos señalar que la idea de juventud -y de jóvenes mujeres-, entre fines del siglo XIX y principios del siglo XX, se configuró a partir de la diferencia u otredad. Como señala Stuart Hall (2010), la estabilidad de las identidades y su significado, se vincula a un ejercicio de oposición binaria fundamental:

\footnotetext{
Es necesaria tanto para la producción de significado, la formación de lenguaje y cultura, para identidades sociales y un sentido subjetivo del sí mismo como sujeto sexuado; y al mismo tiempo, es amenazante, un sitio de peligro, de sentimientos negativos, de hendidura, hostilidad y agresión hacia el "Otro" (Hall, 2010: 428).
}

Esta garantía de un adentro y un afuera se presenta desde múltiples discursos institucionales, científicos y morales en el Chile de la época analizada, produciendo ideas sobre un nuevo sujeto que comienza a incidir en la vida social: los y las jóvenes. De esta forma, la proliferación de discursos regulatorios que se producían desde el Estado principalmente comenzaron a incluir aquellas diferenciaciones de edad desde las que se configurarían (junto con otros agentes de producción de sentido) las formas modernas de comprender la juventud.

\section{Bibliografía}

Aguilera, O. 2014. "La idea de juventud en Chile en el siglo XX. Aproximación genealógica al discurso de las revistas de juventud." Revista Anagramas 12 (24): 141- 160.

Alarcón, R. 2002. Estudios sobre psicología latinoamericana. Lima: Universidad Ricardo Palma.

Dávila, O. 2004. "Adolescencia y Juventud: De las nociones a los abordajes”. Última Década 12 (21): 83-104.

Feixa, C. 1996. "Antropología de las edades". Ensayos de Antropología Cultural. Homenaje a Claudio Esteva-Fabregat. Eds.
Prat J. y Martínez A. Barcelona: Ariel. 319-335.

Foucault, M. 2009. Nacimiento de la biopolítica. Curso del Collège de France (1978-1979). Madrid: Akal. Pre-Textos. 2008. Nietzsche, La genealogía, La historia. Valencia: 2005. Historia de la sexualidad. I. La voluntad del Saber. México: Siglo XXI.

González, Y., Feixa, C. 2012. La construcción histórica de la juventud en América Latina: bohemios, rockanroleros \& 
revolucionarios. Santiago: Cuarto Propio.

Hall, S. 2010. "El espectáculo del Otro". Sin Garantías: Trayectorias y problemáticas en estudios culturales. Stuart Hall. Eds. Restrepo, E., Walsh, C. y Vich, V. Popayán: Envión. 419-446 Joignant, A. 2001. "El lugar del voto. La ley electoral de 1874 y la invención del ciudadano-elector en Chile". Revista Estudios Públicos, 81: 245-275.

Labarca, C. 2008. "Todo lo que usted debe saber sobre las enfermedades venéreas". Por la salud del cuerpo: historia y politicas sanitarias en Chile. Ed. Zárate, M. Santiago: Universidad Alberto Hurtado.

Manzano, V. 2014. The age of youth in Argentina. Culture, Politics \& sexuality from Perón to Videla. North Carolina: The University of North Carolina Press.

Ramos, N., Sepúlveda, C. 2010. "Niñas en los primeros liceos del Estado Chileno". Revista Docencia 40: 59-65.

Reguillo, R. 2012. Culturas juveniles. Formas políticas del desencanto. Buenos Aires: Siglo XXI.

Rinke, S. 2002. Cultura de masas, reforma y nacionalismo en Chile 1910-1931. Santiago: Dibam.

Saa, M. 2014. "Jóvenes delgadas, bellas y blancas: la producción del cuerpo juvenil en la publicidad. El caso de revista Margarita (1930-1940)". Revista Última Década 22 (41): 71-87.
Salazar, G. y Pinto, J. 1999. Historia contemporánea de Chile. Santiago: LOM.

Sánchez, K. 2006. "El ingreso de la mujer chilena a la universidad y los cambios en la costumbre por medio de la ley 1872-1877". Historia 39 (2): 497-529.

Toro, P. 2014. "Formar el cuerpo sano y controlar el mal espíritu. Disciplinas del cuerpo y de las emociones juveniles en la educación pública chilena (C.1813- C.1900)." Formas de control y disciplinamiento. Chile, América y Europa, siglos XVI-XIX. Eds. Gaune, R. y Undurraga, V. Santiago: Uqbar. 262-279. 2012 a. "Dimensiones de la confección de una juventud virtuosa: manuales de urbanidad en Chile (c.1840-c.1900)". Revista Universum 27 (1): 195-205

2012 b. "Desórdenes y juegos de capas en la plaza: estudiantes, espacio público y juventud (San Fernando, c.1870-c.1900). Revista Historia 2 (45):485-502

2010. "Los espacios de la juventud en Chile en el siglo XIX". Revista Docencia 40: 66-74

Urteaga, M., Pérez, J. 2012. "La construcción de lo juvenil en la modernidad y contemporaneidad mexicanas". La construcción histórica de la juventud en América Latina: bohemios, rockanroleros \& revolucionarios. Eds. González, Y. y Feixa C. Santiago: Cuarto Propio. 123-202. 